3. C.E. Kennedy, "Review of Mid- to High-Temperature Solar Selective Absorber Materials" (NREL Report TP-520-31267, NREL, Golden, C0, 2002; www.nrel.gov/csp/troughnet/pdfs/31267.pdf) (accessed January 2008). 4. C.E. Kennedy, H. Price, "Solar Engineering 2005: Proceedings of the 2005 International Solar Energy Conference" (ISEC2005), 6-12 August 2005, Orlando, Florida (NREL Report CP-520-36997, American Society of Mechanical Engineers, New York, 2006; www.nrel.gov/csp/troughnet/ pdfs/36997.pdf) p. 749 (accessed January 2008).
5. C. Kennedy, K. Terwilliger, M. Milbourne, "Development and Testing of Solar Reflectors" (NREL Report CP-520-36582, NREL, Golden, C0, 2005; www.nrel.gov/docs/fy050stify050sti/36582.pdf) (accessed January 2008). 6. L. Moens, D. Blake, "Advanced Heat Transfer and Thermal Storage Fluids" (NREL Report CP-510-37083, NREL, Golden, C0, 2005; www.nrel.gov/docs/ fy050stify050sti/37083.pdf) (accessed January 2008).

7. R.G. Reddy, Z. Zhang, M.F. Arenas, D.M. Blake, High Temp. Mater. Processes 22 (2), 87 (2003)

\title{
Thermoelectrics: Direct Solar Thermal Energy Conversion
}

\author{
Terry M. Tritt (Clemson University, USA), Harald Böttner (Fraunhofer Institut für Physikalische \\ Meßtechnik, Germany), and Lidong Chen (China Academy of Sciences, China)
}

\section{Introduction}

The field of thermoelectricity began in the early 1800 s with the discovery of the thermoelectric effect by Thomas Seebeck. ${ }^{1}$ Seebeck found that, when the junctions of two dissimilar materials are held at different temperatures $(\Delta T)$, a voltage $(V)$ is generated that is proportional to $\Delta T$. The proportionality constant is the Seebeck coefficient or thermopower: $\alpha=-\Delta V / \Delta T$. When the circuit is closed, this couple allows for direct conversion of thermal energy (heat) to electrical energy. The conversion efficiency, $\eta_{\mathrm{TE}}$, is related to a quantity called the figure of merit, $Z T$, that is determined by three main material parameters: the thermopower $\alpha$, the electrical resistivity $\rho$, and the thermal conductivity $\kappa$. Heat is carried by both electrons $\left(\kappa_{\mathrm{e}}\right)$ and phonons $\left(\kappa_{\mathrm{ph}}\right)$, and $\kappa=\kappa_{\mathrm{e}}+\kappa_{\mathrm{ph}}$. The quantity $Z T$ itself is defined as

$$
Z T=\frac{\alpha^{2} \sigma T}{\left(\kappa_{e}+\kappa_{\mathrm{ph}}\right)}
$$

where $\sigma$ is the electrical conductivity. In addition, the thermoelectric efficiency, $\eta_{\mathrm{TE}}$, is given by

$$
\eta_{T E}=\eta_{C}\left(\frac{\sqrt{1+Z T}-1}{\sqrt{1+Z T}+\frac{T_{\mathrm{C}}}{T_{\mathrm{H}}}}\right)
$$

where $\eta_{\mathrm{C}}$ is the Carnot efficiency, $\eta_{\mathrm{C}}=\left(T_{\mathrm{H}}-T_{\mathrm{C}}\right) / T_{\mathrm{H}}$ and $T_{\mathrm{H}}$ and $T_{\mathrm{C}}$ are the hot and cold temperatures, respectively. Thus, a significant difference in temperature (large $\Delta T$ ) is also needed to generate sufficient electrical energy, and the infrared (IR) region of the solar spectrum can supply the needed hot temperature, $T_{\mathrm{H}}$. This is important because IR radiation generates only waste heat in conventional semiconductor-based solar photovoltaic cells.

It was not until the mid-1900s, when semiconductor materials research became prevalent, that thermoelectric materials and devices became more important. ${ }^{2,3}$ Semiconducting materials permit band tuning and control of the carrier concentration, thus allowing optimization of a given set of materials. A thermoelectric couple is made up of $n$-type and $p$-type materials, and in a thermoelectric device, many of these couples are then connected electrically in series and thermally in parallel. The thermal-to-electric energy conversion is a solid-state conversion process that is quiet, has no mechanical parts, and provides long-term stability. Thermoelectric devices can be used either for cooling (Peltier effect) or for power generation (Seebeck effect). ${ }^{4}$ Thus, heat (typically waste heat) can be converted directly into useful electrical energy. Thermoelectric materials and devices was the theme topic of the March 2006 issue of MRS Bulletin, and readers are referred to the articles therein for more detail. ${ }^{4}$

Current thermoelectric materials, as shown in Figure 1, have $Z T=1$, and new materials with $Z T$ values of $2-3$ are sought to provide the desired conversion efficiencies. The current materials exhibit conversion efficiencies of $7-8 \%$ depending on the specific materials and the temperature differences involved. With regard to solar energy conversion, thermoelectric devices will likely utilize the IR spectrum of solar radiation as shown in Figures 2 and 3. For example, a thermoelectric power conversion device with $Z T=3$ operating between $500^{\circ} \mathrm{C}$ and $30^{\circ} \mathrm{C}$ (room temperature) would yield about $50 \%$ of the Carnot efficiency. As shown in Figure 4, ${ }^{5}$ a value of $Z T>4$ does not sig-

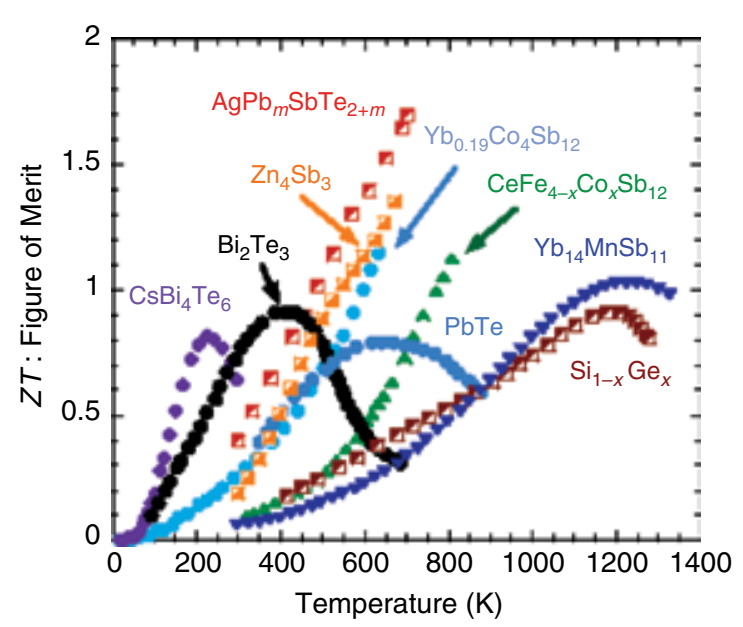

Figure 1. Figure of merit $(Z T)$ as a function of temperature for several high-efficiency bulk thermoelectric materials. 


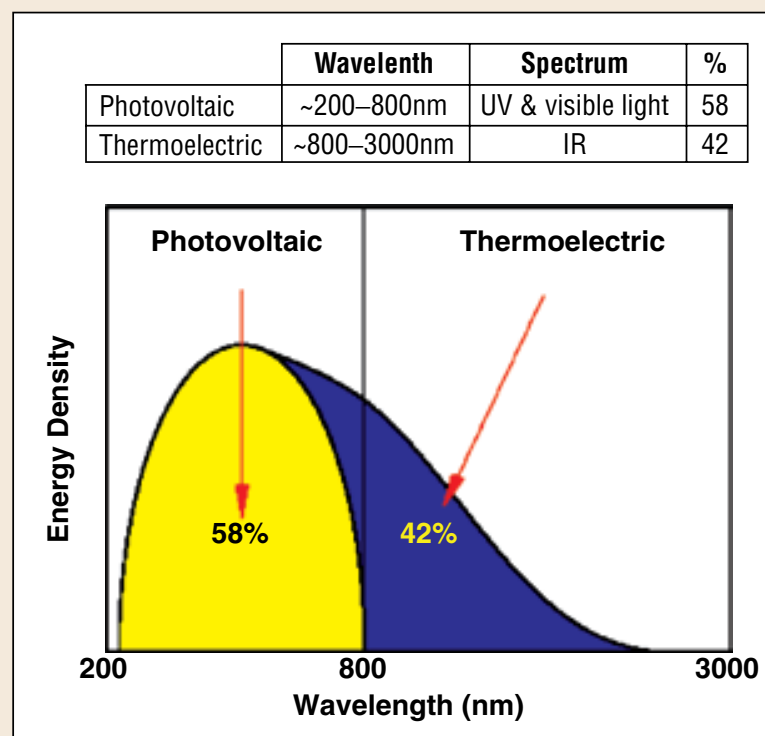

Figure 2. Sun radiates energy as a $6000 \mathrm{~K}$ blackbody radiator with part of the energy in the ultraviolet (UV) spectrum and part in the infrared (IR) spectrum.

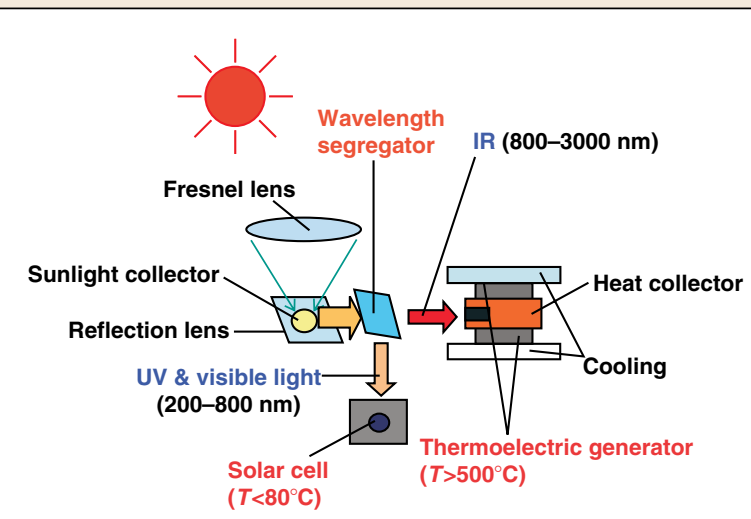

Figure 3. After the solar energy is concentrated, it can be converted into electricity through both photovoltaics (UV spectrum) and thermoelectrics (IR spectrum).

nificantly increase the conversion efficiency over that of a material with $Z T=2-3 .{ }^{5}$ Therefore, we believe that the "Holy Grail" of thermoelectric materials research is to find bulk materials (both $n$-type and $p$-type) with a $Z T$ value on the order of $2-3$ (efficiency $=15-20 \%$ ) with low parasitic losses (e.g., contact resistance, radiation effects, and interdiffusion of the metals) and low manufacturing costs. With respect to solar energy, these materials would need to operate at about $1000 \mathrm{~K}\left(\sim 700^{\circ} \mathrm{C}\right)$. The solar energy conversion process could be envisioned as shown in Figure 3, where a high-efficiency solar collector turns the sunlight (from the IR spectrum) into heat that is then transformed by the thermoelectric devices into usable electricity. In addition, the solar energy could be stored in a thermal bath and transformed into electricity through thermoelectrics when the sun was not shining.

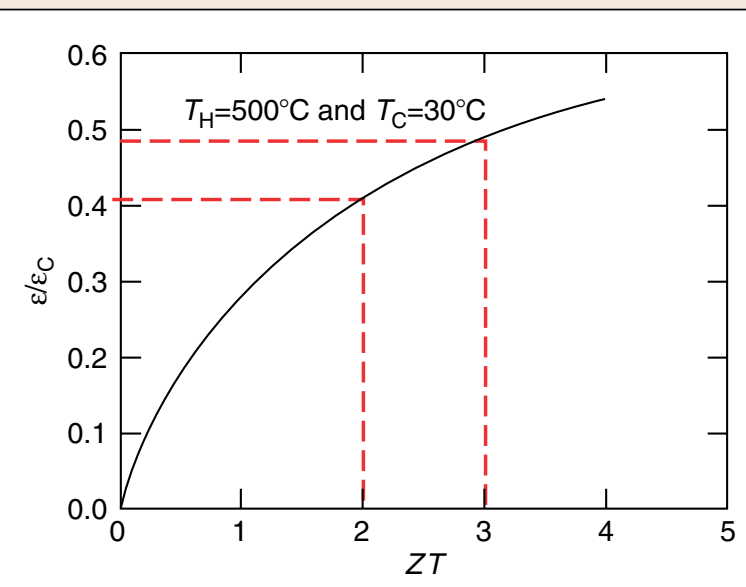

Figure 4. Ratio of the thermoelectric efficiency to the Carnot efficiency $\left(\varepsilon / \varepsilon_{\mathrm{C}}\right)$ as a function of the figure of merit, $Z T$. The maximum efficiency or Carnot efficiency is given by $\varepsilon_{\mathrm{C}}=\left(T_{\mathrm{H}^{-}}\right.$ $\left.T_{\mathrm{C}}\right) / T_{\mathrm{H}}=(773 \mathrm{~K}-300 \mathrm{~K}) /(773 \mathrm{~K})=61 \%$. (Source: Reference 5 , Figure 5a.)

\section{Thermoelectric Applications}

Thermoelectric applications are broad. Thermoelectric materials had their first decisive long-term test with the start of intensive deep-space research. During the Apollo mission, thermoelectric materials were responsible for the power supply, and currently, radioisotope thermoelectric generators (RTGs) are the power supplies $(\sim 350 \mathrm{~W})$ used in deep-space missions beyond Mars. Recently, the Cassini satellite was launched with three RTGs using ${ }^{238} \mathrm{Pu}$ as the thermal energy source and $\mathrm{SiGe}$ as the thermoelectric conversion material. ${ }^{5}$ Smaller self-powered systems such as thermoelectric-powered radios were first mentioned in Russia around 1920; a thermoelectric climate-control system in a 1954 Chrysler automobile shows the scope of this technology. Currently, millions of thermoelectric climate-controlled seats that serve as both seat coolers and seat warmers are being installed in luxury cars. In addition, millions of thermoelectric coolers are used to provide cold beverages. Even wristwatches marketed by Seiko and Citizen and biothermoelectric pacemakers are being powered by the very small temperature differences within the body or between a body and its surroundings.

Thermoelectric materials were previously used primarily in niche applications, but with the advent of broader automotive applications and the effort to utilize waste-heat-recovery technologies, thermoelectric devices are becoming more prominent. The rising costs of fossil fuels have helped spawn a program between the Energy Efficiency and Renewable Energy office of the U.S. Department of Energy and several automotive manufacturers to incorporate thermoelectric waste-heat-recovery technology in the design of heavy trucks. Indeed, without such systems, more than $60 \%$ of the primary energy of fossil fuels is lost worldwide as unusable waste energy; the loss is as high as $70 \%$ in some automobiles.

This field of thermoelectrics also covers forthcoming applications and markets for remote "self-powered" systems for wireless data communications in the microwatt power range, as well as automotive systems and deep-space probes in the intermediate range of hundreds of watts. Researchers hope to produce systems of several kilowatts using waste heat energy from 
stand-alone woodstoves and also transform the huge amounts of waste energy from industrial furnaces and power plants.

\section{The Future of Thermoelectric Materials}

The future expansion of thermoelectric energy conversion technologies is tied primarily to enhanced materials performance along with better thermal management design. The best thermoelectric material should behave as a so-called phononglass-electron-crystal; that is, it should minimally scatter electrons, as in a crystalline material, whereas it should highly scatter phonons, as in an amorphous material. Materials researchers are now investigating several systems of materials including typical narrow-bandgap semiconductors (half-Heusler alloys), oxides, and cage-structure materials (skutterudites and clathrates). ${ }^{4}$ More exotic structures that exhibit reduced dimensionality and nanostructures have been the focus of much recent research, including superlattices, quantum dots, and nanodot bulk materials. Also, recent progress in nanocomposites, mixtures of nanomaterials in a bulk matrix, has generated much interest and hope for these materials. ${ }^{4}$ The emerging field of these thermoelectric nanocomposites appears to be one of the most promising recent research directions. Such nanocomposites could allow for higher $Z T$ values by reducing thermal conductivity while maintaining favorable electronic properties. With new higher efficiency materials, the field of harvesting waste energy through thermoelectric devices will become more prevalent.

The most stable, long-term, and readily available worldwide energy source is that of solar energy. The issue has always been low-cost transformation and storage. Other alternative energy technologies such as fuel cells, wind energy, and thermoelectrics will provide some assistance in meeting our future energy needs. Many hybrid systems will be needed, and thermoelectrics is able to work in tandem with many of these other technologies, especially solar as it can use the heat source provided by solar radiation. Over the past decade, thermoelectric materials have been developed with $Z T$ values that are a factor of 2 larger than those of previous materials. Another $50 \%$ increase in $Z T$ (to $Z T \approx 3$ ) with the appropriate material characteristics and costs will position thermoelectrics to be a significant contributor to our energy needs, especially in waste heat or solar energy conversion. The likelihood of achieving these goals appears to be within reach in the next several years. Furthermore, some contribution from many of these alternative energy technologies such as thermoelectrics will be needed in order to fulfill the world's future energy needs.

\section{References}

1. T.J. Seebeck, Abh. K. Akad. Wiss. 265 (Berlin, 1823).

2. A.F. Ioffe, Semiconductor Thermoelements and Thermoelectric Cooling (Infosearch, London, 1957).

3. H.J. Goldsmid, R.W. Douglas, Br. J. Appl. Phys. 5, 386 (1954).

4. T.M. Tritt, M.A. Subramanian, MRS Bull. 31 (3), 188 (2006); six articles and all references therein.

5. J. Yang, T. Caillat, MRS Bull. 31 (3), 224 (2006).

6. S. Maneewan, J. Hirunlabh, J. Khedari, B. Zeghmati, S. Teekasap, Solar Energy 78, 495 (2005).

\title{
Off-Grid Solar for Rural Development
}

\author{
Wole Soboyejo (Princeton University, USA) and Roger Taylor (National Renewable Energy Laboratory, \\ USA)
}

The World Bank estimates that over two billion people on the planet live their daily lives without access to basic, reliable electric services. ${ }^{1}$ Rural populations in Africa, Latin America, Asia, and island nations need clean water, health services, communications, and light at night. Small, simple, solar electric systems are part of the solution-increasing the quality of life, often at a cost that is less than what is presently being spent for kerosene, dry-cell batteries, and the recharging of automotive batteries that must be lugged to the nearest town on a weekly basis (see Figure 1).

Better technology through advanced materials can reduce costs and improve both the performance and reliability of solar electric systems, but in the field, nothing is "maintenance-free." A loose connection or a dry battery can quickly disable the most sophisticated system. The success of solar systems in remote areas depends not only on competitive cost, but also on the human infrastructure needed to deploy and maintain the systems. Work over the past two decades in pilot deployments of solar photovoltaic (PV) systems has highlighted a few issues that must be addressed if solar PV is to provide the promise of cost-effective, reliable energy solutions in remote regions. ${ }^{2}$

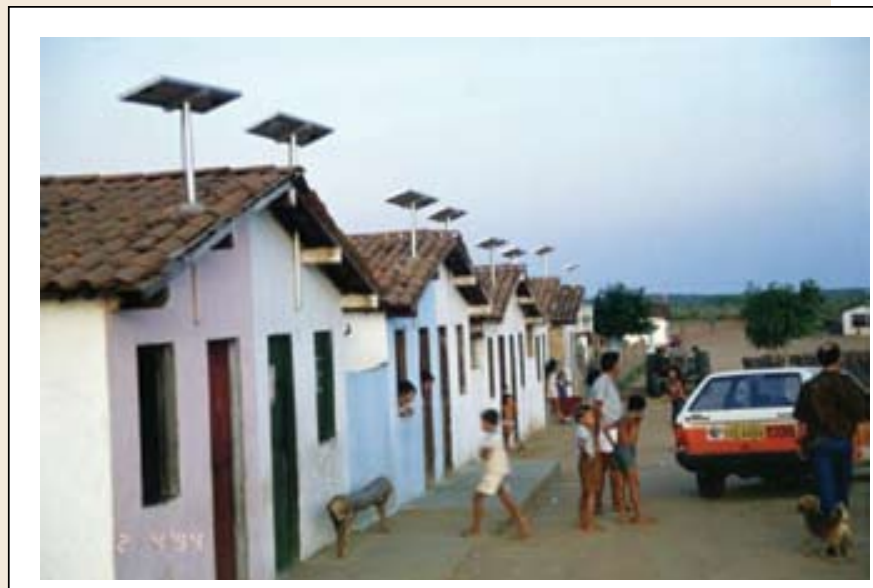

Figure 1. In the village of Irapura, Ceara, Brazil, homes were fitted with $50 \mathrm{~W}$ solar panels for night lighting, television, and radio. A battery stores electricity generated by the solar panel for use at night. (Photograph by Roger Taylor.) 